\title{
Interventions for preventing or treating malnutrition in homeless problem-drinkers: a systematic review
}

\author{
Sharea ljaz ${ }^{1,2^{*}}$ D , Helen Thorley ${ }^{1,2}$, Katie Porter ${ }^{3}$, Clare Fleming ${ }^{4}$, Tim Jones ${ }^{1,2}$, Joanna Kesten ${ }^{1,2,5}$,
} Loubaba Mamluk ${ }^{1,2}$, Alison Richards ${ }^{1,2}$, Elsa M. R. Marques ${ }^{6}$ and Jelena Savović,

\begin{abstract}
Background: Excessive drinking leads to poor absorption of nutrients and homeless problem-drinkers often have nutritionally inadequate diets. Depletion of nutrients such as vitamin B1 can lead to cognitive impairment, which can hinder efforts to reduce drinking or engage with services. This review aimed to assess effectiveness of interventions designed to prevent or treat malnutrition in homeless problem-drinkers.
\end{abstract}

Methods: We systematically searched nine electronic databases and 13 grey literature sources for studies evaluating interventions to improve nutrition in homeless populations, without regional or language restrictions. Screening for inclusion was done in duplicate. One reviewer extracted data and assessed risk of bias, and another checked the extractions. Primary outcomes were nutrition status/deficiency, liver damage, and cognitive function. Secondary outcomes included abstinence, comorbidities, resource use, acceptability and engagement with intervention. Results were synthesised narratively.

Results: We included 25 studies (2 Randomised Controlled Trials; 15 uncontrolled before and after; 7 surveys; 1 case-control). Nine studies evaluated educational and support interventions, five food provision, and three supplement provision. Eight studies evaluated a combination of these interventions. No two interventions were the same, and all studies were at high risk of bias. Nutritional status (intake/ deficiency) were reported in 11 studies and liver function in one.

Fruit and vegetable intake improved with some education and support interventions ( $n=4$ studies) but not others $(n=2)$. Vitamin supplements appeared to improve vitamin deficiency levels in the blood $(n=2)$. Free or subsidised meals $(n=4)$ and food packs $(n=1)$ did not always fulfil dietary needs, but were usually considered acceptable by users. Some multicomponent interventions improved nutrition $(n=3)$ but acceptability varied $(n=3)$. No study reported cost effectiveness.

Conclusions: The evidence for any one intervention for improving malnutrition in homeless problem-drinkers was based on single studies at high risk of bias. Various food and supplement provision interventions appear effective in changing nutritional status in single studies. Educational and multicomponent interventions show improved nutritional behaviour in some studies but not others. Further better quality evidence is required before these interventions can be recommended for implementation. Any future studies should seek the end user input in their design and conduct.

(Continued on next page)

\footnotetext{
* Correspondence: s.ijaz@bristol.ac.uk

${ }^{1}$ The National Institute for Health Research Collaboration for Leadership in Applied Health Research and Care West (NIHR CLAHRC West) at University Hospitals Bristol NHS Foundation Trust, 9th Floor Whitefriars, Lewins Mead, Bristol BS1 2NT, UK

${ }^{2}$ Bristol Medical School, Population Health Sciences, University of Bristol,

Bristol, UK

Full list of author information is available at the end of the article
} 
(Continued from previous page)

Trial registration: Registered with PROSPERO: CRD42015024247.

Keywords: Homeless, Alcoholism, Alcohol, Dependence, Problem-drinking, Malnutrition, Nutrition, Micronutrients, Thiamine, Systematic review, Supplements,

\section{Background}

Problem-drinking is common among homeless people $[1,2]$. Homeless people are not just those sleeping rough on the street, but also include the 'hidden homeless' staying with friends or family, in hostels or bed and breakfasts, or in other vulnerable housing situations [3]. Problem-drinking is a variably defined term and the concept can refer to alcohol abuse without physical dependence $[4,5]$ or beyond 'safe' social drinking [6], or drinking above recommended levels and having problems in life as a result $[7,8]$.

Problem-drinkers tend to obtain a large proportion of their energy intake from alcohol [9, 10]. However, an alcohol-rich diet lacks important vitamins and minerals [11] and also reduces the absorption of nutrients by damaging the gut [12]. When left untreated, this can lead to impairment of cognitive, liver, and immune function [13-16]. Homeless people are at risk of being malnourished due to several factors, such as low income, limited knowledge and choice of food, and lack of cooking and storage facilities [17, 18]. The combined effect of homelessness and problem-drinking increases the risk of malnutrition [19].

Malnutrition costs around $£ 19.6$ billion per year to the public taxpayer in England and accounts for 33\% of the hospital inpatient costs [20]. In December 2016 the homelessness charity Shelter said a lower-end estimate of the number of homeless in England was 250,000 from official datasets [21]. The number of malnourished individuals in sheltered housing in England is estimated to be $22 \%$ higher than that in hospital inpatients [20]. An approach to countering malnutrition is improving the nutritional quality of the food available to the population at risk. This could be achieved by educating people about healthy diet, distribution of nutritious meals or supplements, or advising the providers of food and healthcare how to tackle nutritional deficiencies.

Systematic reviews on interventions that either tackle homelessness or substance abuse in the homeless have been published [22-24], but none have addressed nutrition. There are reviews addressing nutrition in housed problem-drinkers $[25,26]$, however, these will not necessarily be applicable to homeless problem-drinkers. Similarly, nutrition interventions that are in line with NICE guidelines [27] are considered cost effective for addressing malnutrition in the general population [20], but information on cost effective interventions for homeless drinkers is not available for decision makers.

This review aims to bring all these elements together and synthesise evidence on interventions for improving the nutritional status of homeless problem-drinkers [28].

\section{Methods}

Inclusion criteria

We included studies of any controlled or uncontrolled studies evaluating an intervention that aimed to improve the nutritional status, or macro- or micro-nutrient deficiencies in any problem-drinkers experiencing homelessness. We used the UK definition of homelessness in this review which includes: sleeping rough (outside); residing in temporary accommodation such as hostels, bed and breakfasts or night shelters; staying on a temporary basis with family or friends ('sofa surfers'); currently housed people who are at risk of being evicted; and currently housed people who cannot stay because they cannot afford to stay, the home is in a very poor condition or they are subject to violence, abuse or threats in the home [29]. Problem-drinking is a commonly used term with no agreed definition. We therefore included all definitions of problem-drinking, as defined by included study authors [28].

We did not restrict inclusion of studies based on reported outcomes. The primary outcomes of interest for this review were: nutrition status or deficiencies; liver or bone marrow damage; and cognitive function. Secondary outcomes included: mortality; suicide; incidence of acute or chronic gastritis or pancreatitis; quality of life or wellbeing measures; and abstinence. We also collected process outcomes such as resource use, and engagement with or acceptability of interventions.

We excluded position papers; editorials; commentaries; qualitative studies; interventions solely aimed at improving the housing status of individuals or focused solely on reducing or stopping alcohol intake; institutionalised people; studies where entire communities are homeless (e.g. refugees or occupiers of slums or shanty towns). We also excluded studies on orphans or children in state care if not part of homeless families.

\section{Literature searches and study selection}

A search of nine electronic databases and 13 grey literature sources was conducted. References of included studies were 
screened and authors were contacted to find any additional studies or data. The search was published in the protocol [28] and is up to date until 16th November 2016.

References identified in searches were screened in duplicate with disagreements resolved by discussion or a third reviewer. Identified relevant papers were read in full and assessed for inclusion in duplicate, with disagreements resolved by a third reviewer. Experts and homelessness charities were contacted to find unpublished studies and data.

\section{Data extraction}

We extracted study details including aim of the study, country, participant characteristics, sample size; outcomes reported; and outcome data including treatment effect estimates, $p$-values, and confidence intervals. Data were extracted by one reviewer and checked by another. Discrepancies were resolved through discussion (with a third reviewer where necessary). Where data were unclear, we attempted to contact the authors for clarification.

\section{Risk of bias assessment}

Risk of bias was assessed as part of data extraction. The Cochrane risk of bias tool [30] was used for the randomised controlled trials (RCTs) and the criteria listed by the Cochrane Effective Practice and Organisation of Care (EPOC) Group were used for other types of studies [31].

\section{Data synthesis}

Meta-analysis was inappropriate because studies were heterogeneous with respect to their populations, interventions, and outcomes. Instead we carried out a narrative synthesis.

We analysed studies by intervention type: education/information and support; food provision; supplement or fortification; multicomponent interventions. The findings were summarized in tables for the main outcomes.

\section{Results}

\section{Description of included studies}

Results of the search

Electronic searches resulted in 9189 citations. Twenty seven other references were identified in complimentary searches (contacting authors/ organisations, reference screening). In addition, we identified two further studies through contacts with subject experts $[32,33]$ but the authors did not provide sufficient information to assess eligibility to date. We included 25 studies reported in 37 articles / reports and excluded 257 papers (web appendix). The selection process and reasons for exclusion are shown in the PRISMA flowchart (Fig. 1).

\section{Included studies}

Of the 25 studies included, the majority $(n=12)$ were from the USA [34-45], and the rest were geographically diverse. Table 1 provides the characteristics of all included studies. Two studies [34, 41] were RCTs, both from the USA; fifteen were uncontrolled before and after (UBA) studies [35-37, 39, 40, 43, 44, 46-53]; seven were surveys [38, 42, 45, 54-57]; and one was a case-control study using a historical control sample [58].

Studies varied widely in sample size from 5 participants [53] to 128,365 [42], with a median of 50. Most studies $(n=17)$ included less than 100 participants. The total number of participants included in this review is 131,054 . Most studies $(n=9)$ did not report on type of homelessness. Six included shelter dwelling participants only [37, 39-41, 43, 50] while no study included just rough sleeping participants. Problem-drinking was not always defined. Only two studies provided a clear definition of problem-drinking as more than $80 \mathrm{~g}$ alcohol intake per session or per day $[46,56]$, while other studies used terms such as 'alcoholics', 'alcohol dependency', 'overt alcohol problem,' 'drinking at risky levels', or 'seeking counselling for alcohol'. Proportion of problemdrinkers in the study population also varied (median $45 \%$, IQR $26.5 \%$ - 64\%) across studies that reported this information.

Interventions assessed in included studies were grouped into four broad categories based on the different approaches to addressing malnutrition:

1. Education, information or support

2. Supplements (including vitamin injections or tablets, or fortified food products)

3. Food provision (including hot meals or food rations)

4. Multicomponent interventions, where studies combined more than one of the above approaches

Educational, information, and support interventions were the most common $(n=9)$ [34, 37-39, 43, 44, 50, 53]. These included motivational interviewing with nutrition information over the phone [50], a one-off lecture [48], interactive group workshops [34, 37, 43], and full curriculums on nutrition and diet [39, 44,53]. Three studies assessed the effect of supplements and fortification. These included oral or injectable multivitamin supplements [46, 54] and a vitamin-fortified chocolate paste [56]. Five studies tested food provision interventions $[51,52,55,57,58]$ ranging from prepared meals provided within organisations $[55,57]$ and access to prepared meals at specified cafes $[51,52]$ to daily food packages given to clients at a tuberculosis clinic [58]. Multicomponent interventions were assessed in eight studies [35, 36, 40-42, 45, 47, 48]. The combination of interventions included nutrition counselling on harm reduction (e.g. to eat before drinking) 


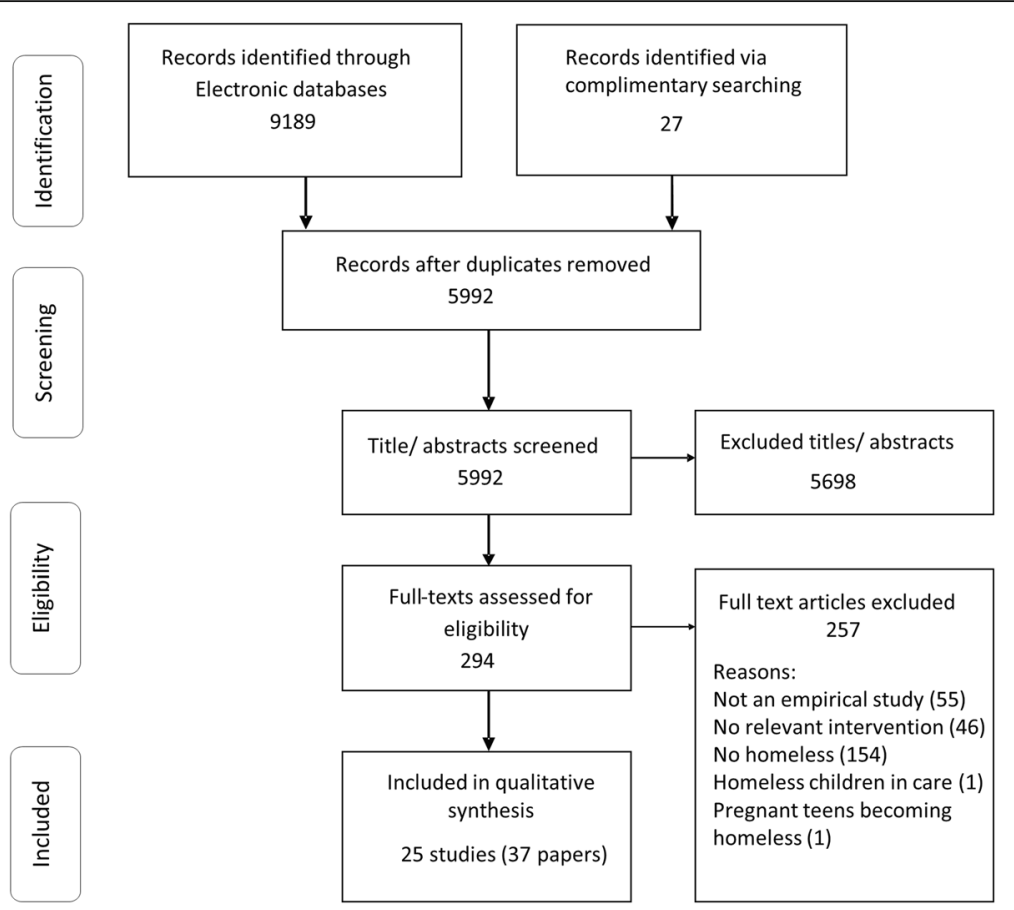

Fig. 1 PRISMA flow diagram of the review process

with naltrexone detoxing [35], provision of education and kitchen facilities [47], provision of food along with kitchen facilities [45], education sessions with food and physical activity [40, 41], support sessions, recreational activities along with transport tickets, and free meals [49], Women, Infants and Children (WIC) programme [42], and addition of group nutrition education, health checks, and food pack vouchers to the WIC programme [36].

\section{Risk of bias in included studies}

All studies were considered to be at a high risk of bias (Fig. 2). In the two RCTs the sequence generation and concealment of allocation were both rated 'unclear'. None of the studies reported attempts to adequately prevent knowledge of allocation to intervention (blinding) either for participants, providers or outcome assessors. Only two [41, 43] out of the 25 studies adequately addressed incomplete outcome data in their analyses. The majority of the studies $(n=19)$ were also judged to be at high risk for the knowledge of allocated intervention to have affected data collection (based on Cochrane EPOC criteria) [31].

\section{Findings}

\section{Primary outcomes}

Nutritional status Nutritional status measures were reported in 13 studies [34, 39-41, 43-46, 50-54]. Of these, three studies reported micronutrient deficiency in blood samples [43, 46, 54] and ten reported on nutritional intake [34, 39-41, 44, 45, 50-53].

Education, information or support interventions Educational sessions of varying intensity and duration were assessed in four studies [34, 39, 44, 53]. One involved motivational telephone interviewing [50], one was a single session on food hygiene and nutrition along with a cooking competition [49], and one involved life skill workshops [37]. One study assigned a case manager to provide information and support to optimise the uptake of the Supplemental Nutrition Program for WIC [38]. Most of these were aimed at change in nutritional intake $[34,39,43,44$, $50,53]$. The studies varied in design (one RCT, others uncontrolled before after studies) and outcome assessments (attempts to increase intake, frequency, or amount of intake). The effects were not consistent across studies, however, the majority indicate that education and support interventions could contribute to improved nutritional behaviour, i.e. eating healthier food (Table 2).

Supplement provision interventions The oral [54] and injectable [46] multivitamin supplements were effective in lowering blood indictors of deficiency (Table 2). However, no longer term health or disease outcomes were measured.

Food provision interventions One study [51] reported on a large-scale state supported intervention providing 


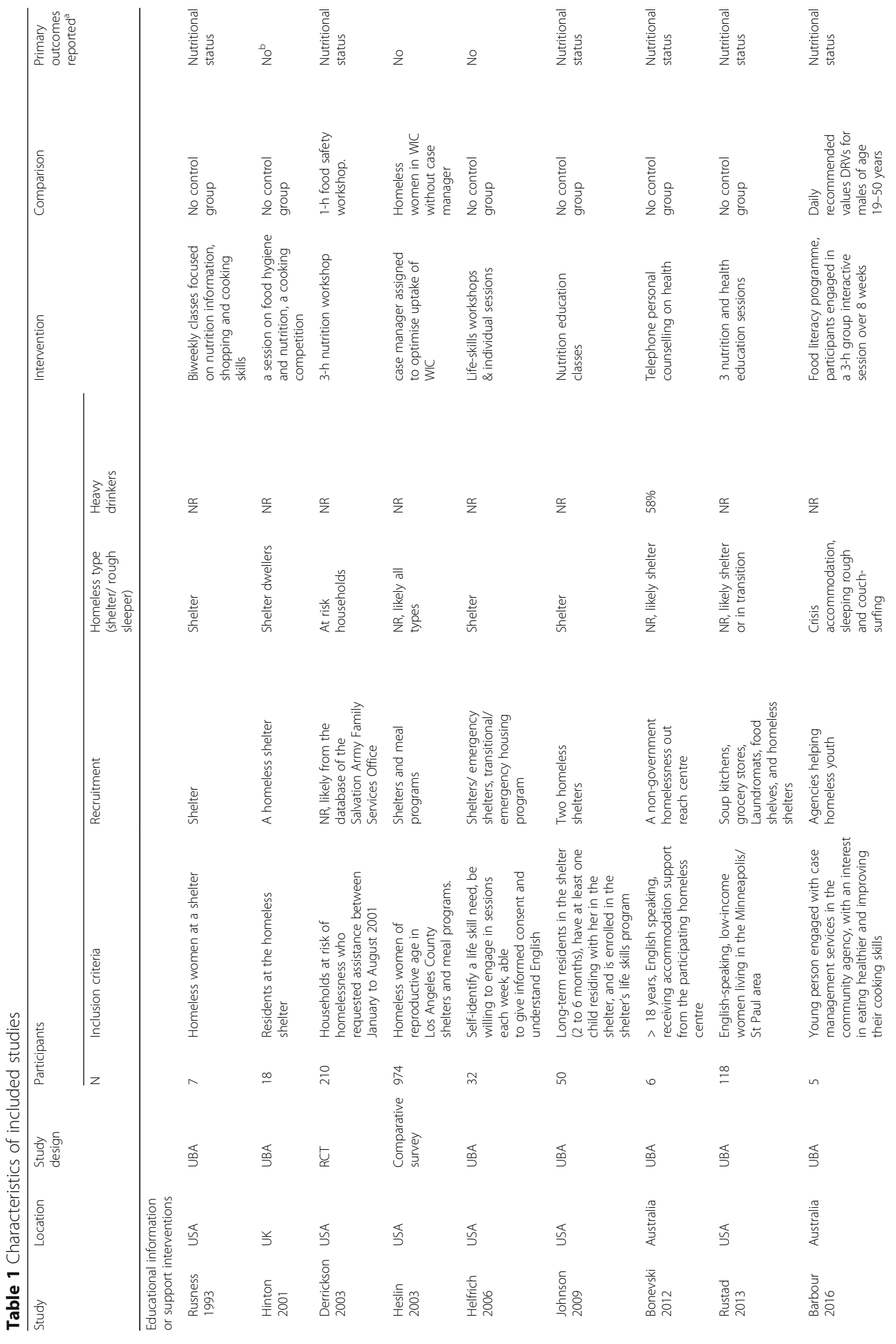




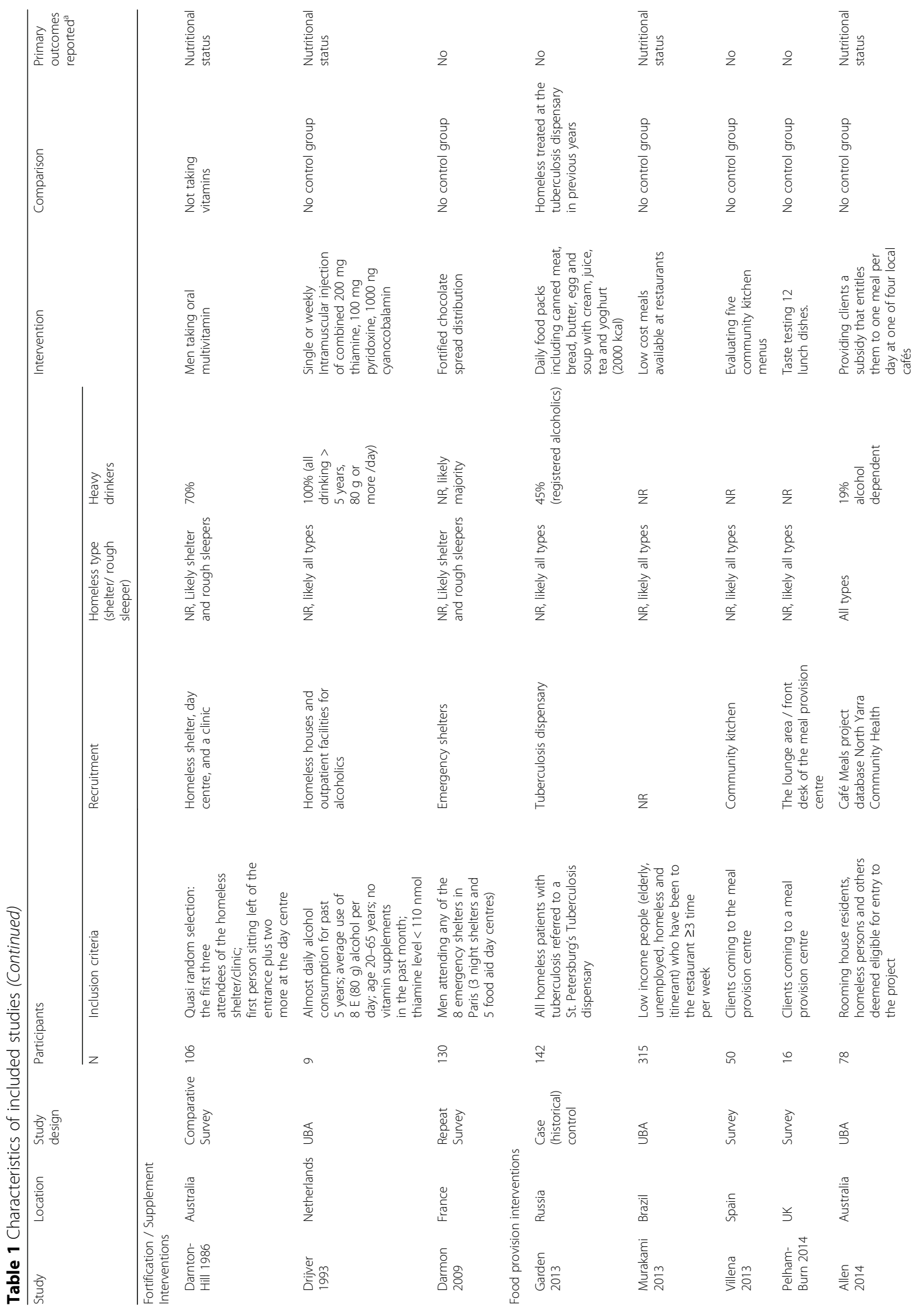




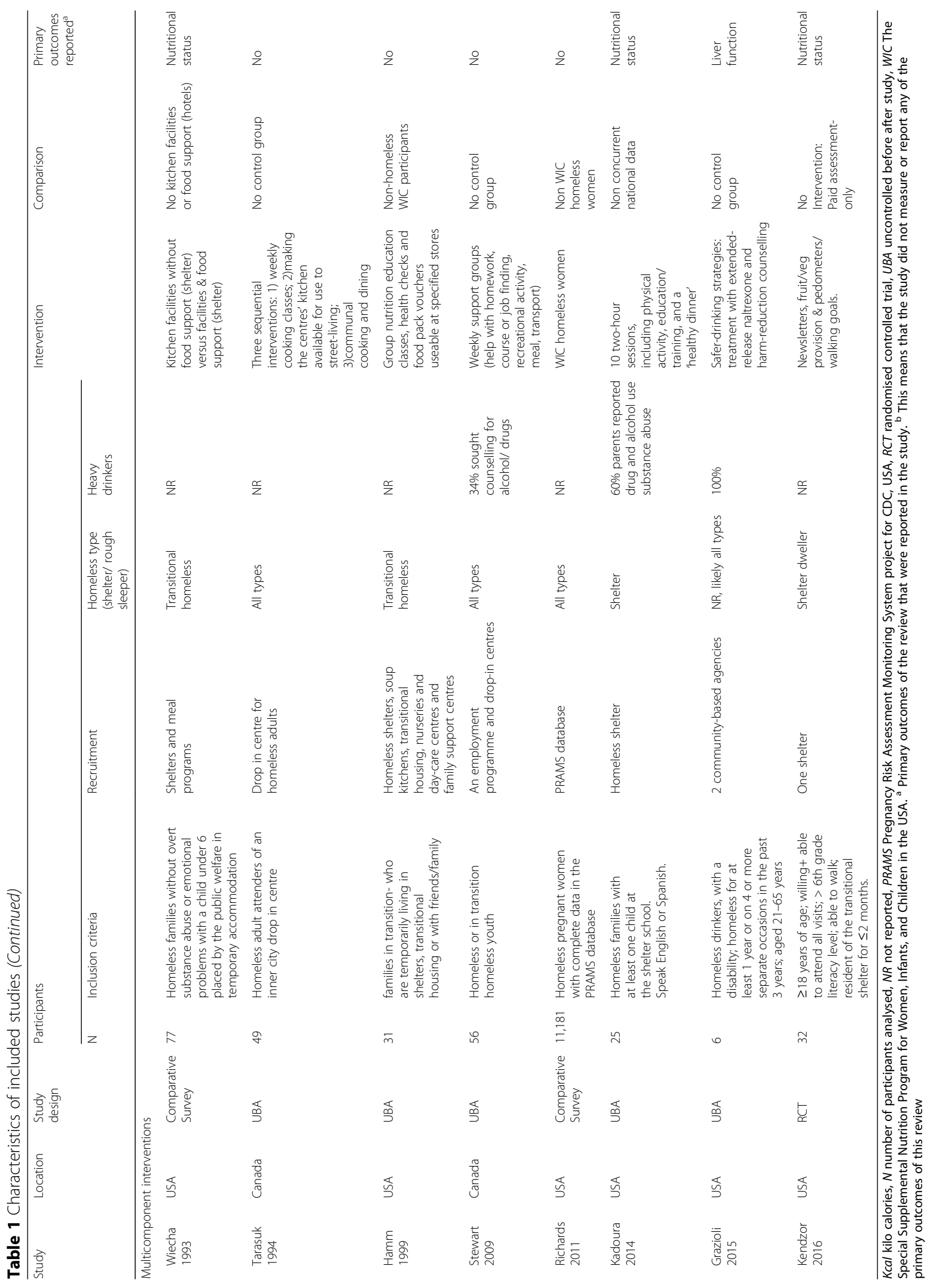




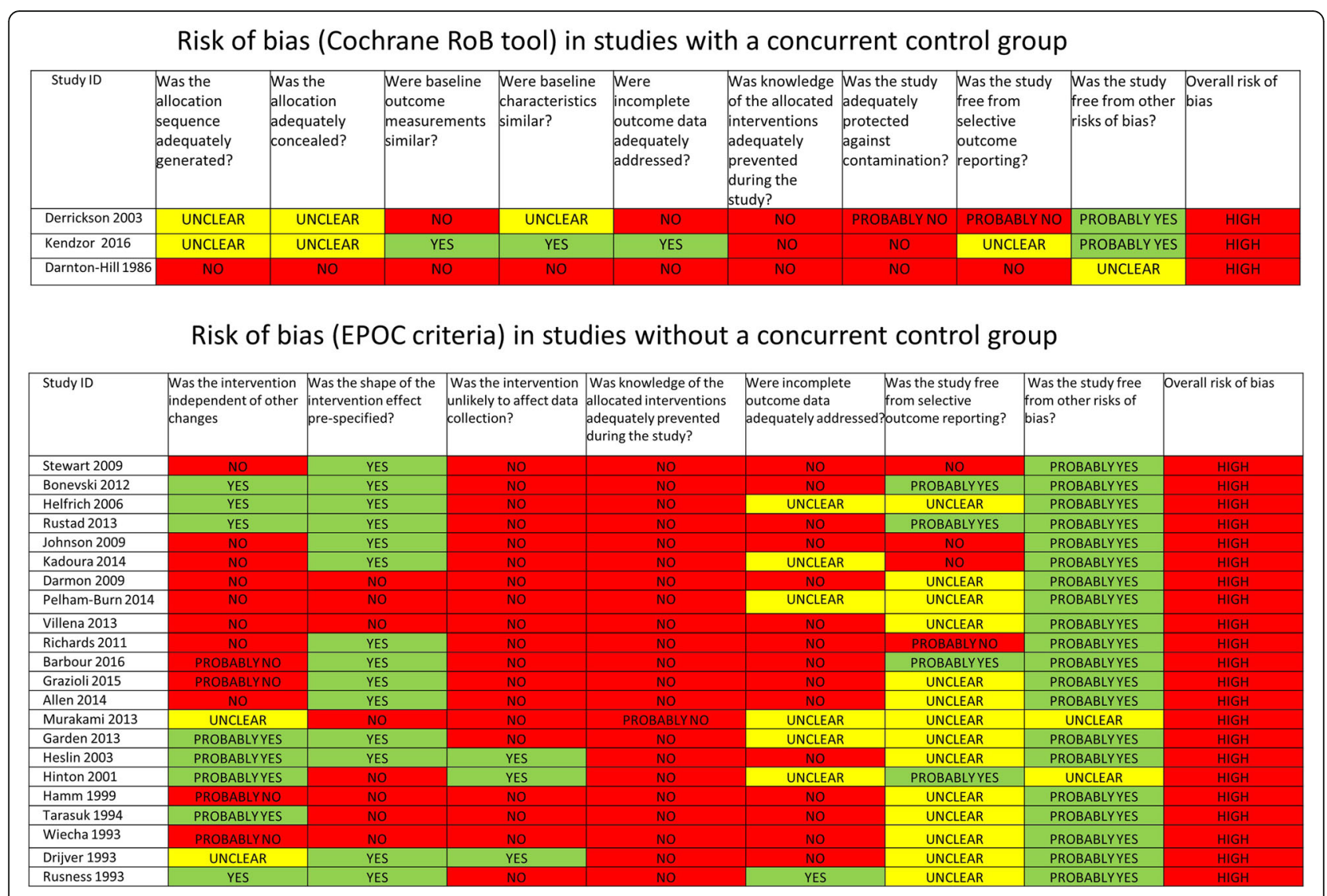

Fig. 2 Risk of bias in included studies

healthy meals at designated cafes and diners. The authors reported energy intake to be below recommended levels for clients eating there daily. One study providing food subsidy for meals at a local cafe [52] reported that people ate more frequently, had weight gain and learnt food preparation skills and healthy eating habits, but quantitative data were not reported (Table 2).

Multicomponent interventions Nutrition intake changes were reported in three studies [40, 41, 45]. All indicated a beneficial effect of the multicomponent interventions on healthier food intake (Table 2).

Liver function Only one study [35] evaluating a multicomponent intervention (naltrexone detoxing and harm reduction counselling) reported liver function tests (mean aspartate transaminase and alanine transaminase levels) for the intervention group only, and found no difference between before and after measurements (Table 2).

\section{Secondary outcomes}

Change in drinking behaviour was reported in three studies [35, 40, 49]. Several studies assessed some aspects of success of implementation of their intervention/ programme, such as the acceptability of the intervention [35, 55-57], or attendance and intervention/ programme completion [36, 41, 48, 58]. Cost of interventions was reported in four studies [51, 54, 56, 58]. However, no study reported cost effectiveness analyses.

Drinking behaviour Three studies, all assessing multicomponent interventions reported this outcome. Kadoura [40] reported a small non-significant decrease (Cohen's $\mathrm{d}=0.15 ; p=0.15$ ) in mean alcohol consumption compared to baseline in the intervention group of homeless families. Stewart et al. [49] reported $26 \%$ fewer participants drinking at the end compared to the midpoint assessment. Grazioli et al. [35] indicated the intervention (naltrexone + nutritional counselling) may lead to more drinking.

Measures of implementation success Eight studies reported some measure of implementation success (see Web appendix for details). Poor attendance (0-22\%) was seen for an intervention using education sessions with a cooking competition at a shelter [48]. Higher treatment completion rates were seen in a tuberculosis 
Table 2 Primary outcomes in included studies

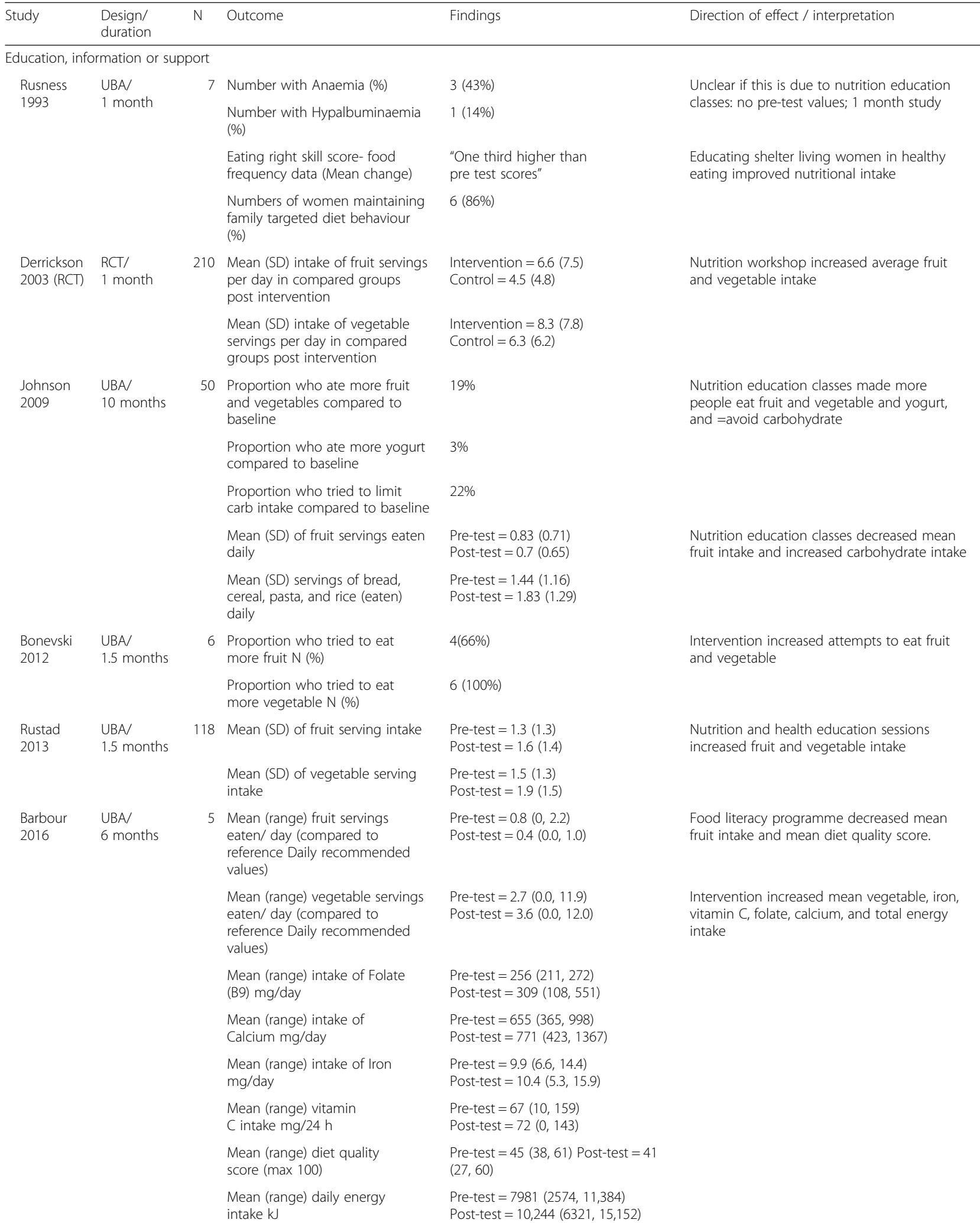


Table 2 Primary outcomes in included studies (Continued)

\begin{tabular}{|c|c|c|c|c|c|}
\hline Study & $\begin{array}{l}\text { Design/ } \\
\text { duration }\end{array}$ & $\mathrm{N}$ & Outcome & Findings & Direction of effect / interpretation \\
\hline \multicolumn{6}{|c|}{ Supplement provision } \\
\hline \multirow{12}{*}{$\begin{array}{l}\text { Darnton- } \\
\text { Hill } 1986\end{array}$} & \multirow{12}{*}{$\begin{array}{l}\text { Comparative } \\
\text { survey/ } \\
24 \text { months }\end{array}$} & \multirow[t]{12}{*}{106} & $\%$ deficient in vitamin B1 & $N \vee g p=45 \vee g p=25$ & \multirow{7}{*}{$\begin{array}{l}\text { Oral vitamin supplements reduced the } \\
\text { number of people with vitamin deficiency }\end{array}$} \\
\hline & & & $\%$ deficient in vitamin B6 & $N V g p=63 \vee g p=21$ & \\
\hline & & & $\%$ deficient in vitamin C & $\mathrm{NV} g \mathrm{p}=29 \mathrm{Vgp}=10$ & \\
\hline & & & $\%$ deficient in vitamin B12 & $\mathrm{NV} g \mathrm{p}=0 \vee \mathrm{gp}=0$ & \\
\hline & & & $\%$ deficient in folate (B9) & $N V g p=80 \vee g p=49$ & \\
\hline & & & $\%$ deficient in iron & $\mathrm{NV} g \mathrm{p}=12 \mathrm{~V} g \mathrm{p}=15$ & \\
\hline & & & $\%$ deficient in zinc & $\mathrm{NV} g \mathrm{p}=25 \mathrm{Vgp}=25$ & \\
\hline & & & Mean (SD) levels of TPP\% & $\mathrm{NV} g \mathrm{p}=15.3(10.5) \vee \mathrm{gp}=10.5(9.9)$ & \multirow{5}{*}{$\begin{array}{l}\text { Oral vitamin supplements don't always i } \\
\text { mprove group mean levels of vitamins }\end{array}$} \\
\hline & & & $\begin{array}{l}\text { Mean (SD) levels of vitamin } \\
\text { B6 P5P\% }\end{array}$ & $\mathrm{NV} g \mathrm{p}=57(26.6) \vee \mathrm{gp}=36.2(31.4)$ & \\
\hline & & & $\begin{array}{l}\text { Mean (SD) levels of vitamin } C \\
\mu \mathrm{mol} / \mathrm{L}\end{array}$ & $\mathrm{NV} g \mathrm{p}=34.9(16.2) \vee \mathrm{gp}=72.6$ (35.2) & \\
\hline & & & $\begin{array}{l}\text { Mean (SD) levels of serum Folate } \\
\mathrm{ng} / \mathrm{ml}\end{array}$ & $\mathrm{NV} g \mathrm{p}=3.6(4.0) \vee \mathrm{gp}=5.2(4.0)$ & \\
\hline & & & $\begin{array}{l}\text { Mean (SD) levels of vitamin B } \\
12 \mathrm{pmol} / \mathrm{L}\end{array}$ & $N V g p=341(203) \vee g p=433(223)$ & \\
\hline \multirow[t]{4}{*}{$\begin{array}{l}\text { Drijver } \\
1993\end{array}$} & \multirow[t]{4}{*}{ UBA/ NR } & \multirow[t]{4}{*}{9} & Mean Tk activity increase (units) & $\begin{array}{l}\text { Single injection: Before }=9.6 ; \text { day } \\
14=11.8\end{array}$ & \multirow[t]{4}{*}{$\begin{array}{l}\text { Multivitamin injection keeps vitamin } \\
\text { levels up for } 14 \text { days. }\end{array}$} \\
\hline & & & & $\begin{array}{l}\text { Weekly injection: Before }=10.2 ; \\
\text { day } 7=12 ; \text { day } 21=11.2 ; \text { day } 35=12\end{array}$ & \\
\hline & & & Mean TDP effect (\%) & $\begin{array}{l}\text { Single injection: Before }=18 \text {; day } \\
14=9\end{array}$ & \\
\hline & & & & $\begin{array}{l}\text { Weekly injection: } \text { Before }=17 \\
\text { day } 7=3 ; \text { day } 21=5 \\
\text { day } 35=5\end{array}$ & \\
\hline \multicolumn{6}{|c|}{ Food provision } \\
\hline \multirow[t]{5}{*}{$\begin{array}{l}\text { Murakami } \\
2013\end{array}$} & \multirow[t]{5}{*}{ UBA/ NR } & \multirow[t]{5}{*}{315} & $\begin{array}{l}\% \text { of Clients eating below } \\
\text { recommended energy intake }\end{array}$ & 79.0 & \multirow{5}{*}{$\begin{array}{l}\text { The hot meals do not fulfil energy needs for } \\
\text { most participants, and even though provide } \\
\text { a high fibre diet, still contribute to higher } \\
\text { than recommended fat and saturate intake } \\
\text { in many participants. }\end{array}$} \\
\hline & & & $\begin{array}{l}\text { Mean (SD) } 24 \text { h Energy intake } \\
\text { kcal }\end{array}$ & $948.55(108.75)$ & \\
\hline & & & $\begin{array}{l}\text { Proportion with above average } \\
\text { fibre intake }\end{array}$ & $62.9 \%$ & \\
\hline & & & $\begin{array}{l}\text { Proportion with saturated fat } \\
\text { above the recommended levels }\end{array}$ & $22 \%$ & \\
\hline & & & $\begin{array}{l}\text { Proportion with cholesterol } \\
\text { intake above the recommended } \\
\text { levels }\end{array}$ & $41 \%$ & \\
\hline Allen 2014 & $\begin{array}{l}\text { UBA/ } \\
12 \text { months }\end{array}$ & 78 & $\begin{array}{l}\text { Proportion eating more } \\
\text { frequently and gaining weight }\end{array}$ & $\begin{array}{l}\text { Numbers not reported: "many clients } \\
\text { eat more frequently, and experience } \\
\text { positive weight gain" }\end{array}$ & $\begin{array}{l}\text { A subsidy to have one meal per day } n \text { may } \\
\text { increase food intake }\end{array}$ \\
\hline \multicolumn{6}{|c|}{ Multicomponent interventions } \\
\hline $\begin{array}{l}\text { Kendzor } \\
2016\end{array}$ & $\begin{array}{l}\text { RCT/ } \\
1 \text { month }\end{array}$ & 32 & $\begin{array}{l}\text { Mean (cups) vegetable and fruit } \\
\text { intake }\end{array}$ & $\begin{array}{l}\text { Intervention }=3.56 \text {; controls }=2 ; \\
\mathrm{MD}=1.5 \text { cups more in intervention } \\
\text { at } 4 \text { week follow up }\end{array}$ & $\begin{array}{l}\text { Newsletters, fruit/vegetables \& pedometers } \\
\text { with walking goals are able to increase fruit } \\
\text { and vegetable intake }\end{array}$ \\
\hline \multirow[t]{2}{*}{$\begin{array}{l}\text { Wiecha } \\
1993\end{array}$} & \multirow[t]{2}{*}{$\begin{array}{l}\text { Comparative } \\
\text { survey/ } \\
9 \text { months }\end{array}$} & 77 & $\begin{array}{l}\text { Mothers' Mean }(\mathrm{mg}) \text { Vitamin } \\
\text { B6 intake per } 1000 \mathrm{kcal}\end{array}$ & $\begin{array}{l}\text { Kitchen facilities with or without food } \\
\text { support (shelter group) =0.68; } \\
\text { no facilities or food } \\
\text { (hotels group) }=0.55\end{array}$ & \multirow[t]{2}{*}{$\begin{array}{l}\text { Provision of full kitchen facilities with or } \\
\text { without added food support can increase } \\
\text { intake of important micronutrients but not } \\
\text { total protein or energy intake for families }\end{array}$} \\
\hline & & & $\begin{array}{l}\text { Mothers' Mean }(\mathrm{mg}) \text { Vitamin } \\
\text { C intake per } 1000 \mathrm{kcal}\end{array}$ & $\begin{array}{l}\text { Kitchen facilities with or without food } \\
\text { support (shelter group) }=61 ; \text { no } \\
\text { facilities or food(hotels) group }=41\end{array}$ & \\
\hline
\end{tabular}


Table 2 Primary outcomes in included studies (Continued)

\begin{tabular}{|c|c|c|c|c|c|}
\hline Study & $\begin{array}{l}\text { Design/ } \\
\text { duration }\end{array}$ & N & Outcome & Findings & Direction of effect / interpretation \\
\hline & & & $\begin{array}{l}\text { Mothers' Mean }(\mathrm{g}) \text { protein } \\
\text { intake per } 1000 \mathrm{kcal}\end{array}$ & $\begin{array}{l}\text { Kitchen facilities with or without food } \\
\text { support (shelter group) }=35 \text {; no } \\
\text { facilities or food(hotels) group }=33\end{array}$ & \\
\hline & & & $\begin{array}{l}\text { Mothers' Mean Energy (kcal) intake } \\
\text { per } 1000 \text { kcal }\end{array}$ & $\begin{array}{l}\text { Kitchen facilities with or without food } \\
\text { support (shelter group) =1980; no } \\
\text { facilities or food(hotels) group }=2016\end{array}$ & \\
\hline \multirow[t]{2}{*}{$\begin{array}{l}\text { Kadoura } \\
2014\end{array}$} & $\begin{array}{l}\text { UBA/ } \\
1 \text { month }\end{array}$ & 25 & $\begin{array}{l}\text { Mean change in frequency } \\
\text { of fruit and vegetable intake } \\
\text { (Cohen's D) }\end{array}$ & 0.56 & $\begin{array}{l}\text { Family physical activity, education/training, } \\
\text { and a 'healthy dinner 'increased both amount and } \\
\text { frequency of fruit and vegetable intake }\end{array}$ \\
\hline & & & $\begin{array}{l}\text { Mean change in amount } \\
\text { of fruit and vegetable intake } \\
\text { (Cohen's D) }\end{array}$ & 0.87 & \\
\hline \multirow[t]{2}{*}{$\begin{array}{l}\text { Grazioli } \\
2015\end{array}$} & $\begin{array}{l}\text { UBA/ } \\
3 \text { months }\end{array}$ & 6 & AST levels median (IQR) units & $\begin{array}{l}\text { Baseline }=64.5(34.5,95.5) \\
\text { follow up }=60(29.25,90.5) \\
\text { Wilcoxon signed rank } \\
\text { test }=-0.77\end{array}$ & $\begin{array}{l}\text { Detoxification with naltrexone and harm- } \\
\text { reduction counselling with a focus on better } \\
\text { diet habits led to no change in liver function } \\
\text { tests post intervention }\end{array}$ \\
\hline & & & ALT levels median (IQR) units & $\begin{array}{l}\text { Baseline }=40.5(30.25,51.5) \\
\text { follow up }=32(21.5,56.75) \\
\text { Wilcoxon signed rank } \\
\text { test }=-0.7\end{array}$ & \\
\hline
\end{tabular}

ASTaspartate transaminase, $A L T$ alanine transaminase, $B 1$ thiamine, $B 2$ riboflavin, $B 3$ niacin, $B 5$ pantothenic acid, $B 6$ pyridoxine, $B 7$ biotin, $B 9$ folic acid, $B 12$ cobalamins, $C$ ascorbic acid, $g$ gram, $g p$ group, $k c a l$ kilocalories, $k J$ kilojoules, $L$ litre, $M D$ mean difference, $m g$ milligram, $m m o l$ millimoles, $n m o l$ nanomoles, $\mu \mathrm{mol}$ micromoles, $N$ number of participants, $N R$ not reported, $N V$ no vitamin, pmol picomoles, P5P pyridoxal 5 phosphate, $R C T$ randomised controlled trial, $S D$ standard deviation, Tk transketolase, TDP thiamine diphosphate, TPP thiamine pyrophosphate, UBA uncontrolled before and after study, $V$ vitamin

clinic for homeless with a daily food pack provision [58]. In taste testing carrot cake, beef burger, and apple crumble were liked the most in a study in the UK [57], while a study in Spain [55] found that dairy, fruits and beans were favoured, however both reported a low preference for fish. There was high acceptability for the vitamin fortified chocolate spread packets [56].

High attendance rates and perceived effectiveness were observed in a study that provided education, food provision and goal setting [41]. In contrast, low acceptability and perceived effectiveness were seen in a study of naltrexone detoxing with counselling for better eating [35]. Group nutrition education and health checks part of the WIC intervention were acceptable to homeless families. However, food voucher uptake and use was low [36] and reasons for this low uptake of vouchers were: transiency, loss of the identification documents, loss of vouchers, lack of transport, and lack of time. One third of these families reported difficulty carrying a large amount of groceries, and $23 \%$ did not think the food met their needs fully.

Cost and resource use No studies reported cost effectiveness or provided enough data to assess cost effectiveness. Five studies reported cost and resource outcomes for the interventions tested $[47,51,54,56,58]$ (Table 3). One other study [57] recorded information on costs of meals provided but did not report this data in the paper. The table shows that although some of the cost information dates as far back as the 1980s and the comparisons are indirect, vitamin tablet supplementation could be cheaper than other interventions.

Other outcomes (detailed in web appendix) reported in included studies were life skills $[37,53]$, infant health and health visits by mothers $[42,43,49,50]$, physical activity $[41,50]$, access to shelter and food [38], and social outcomes such as loneliness and enjoyment $[47,49]$.

\section{Discussion}

\section{Summary of findings}

To our knowledge, this is the first review of the evidencebase on the effectiveness and costs of interventions for malnutrition in the homeless problem-drinking population. We included 25 studies assessing four broad categories of interventions. We found that in terms of nutritional status, educational interventions may increase fruit and vegetable intake, but this was not consistent across studies. A fortnightly multivitamin injection or daily multivitamin oral tablet could prevent vitamin deficiencies. A daily multivitamin fortified chocolate spread pack was acceptable but evidence of effectiveness was not reported. Free or subsidised meals or daily food packs also appeared acceptable but did not always fulfil adult energy needs. Three multicomponent intervention studies assessed nutritional status and all showed improved nutritional intake. In terms of implementation success or acceptability, provision of food or kitchen facilities were usually well received, but education in combination with detox or a cooking competition, or food vouchers that required money and time to be redeemed were not favoured. 
Table 3 Cost and resource use in included studies

\begin{tabular}{lll}
\hline Study & Intervention & Outcome Measure and Findings (USD) $^{\mathrm{a}}$ \\
\hline Darnton-Hill 1986 & Vitamin C, B complex, and thiamine regimen & Cost / day AUD (USD): 0.168 (0.12) \\
& B complex capsule & Cost / day AUD (USD): 0.085 (0.06) \\
& Thiamine tablet $50 \mathrm{mg}$ & Cost / day AUD (USD): 0.035 (0.03) \\
& Vitamin C tablet $500 \mathrm{mg}$ & Cost / day AUD (USD): 0.048 (0.03) \\
& Vitamin fortified chocolate spread plus street food & Cost of one RDA diet EUR(USD): 3.64 (5.07) \\
Darmon 2009 & Food aid meal along with street food & Cost of one RDA diet EUR(USD): 4.78 (6.6) \\
& Street food alone & Cost of one RDA diet EUR(USD): 5.6 (7.7) \\
Garden 2013 & 2000 kcal day-food pack & Average cost USD: $1.3-1.5$ \\
Murakami 2013 & Breakfast (400 kcal) & Cost of one meal R\$ (USD): 0.5 (0.15) \\
Tarasuk 1994 & Lunch (1200 kcal) & Cost of one meal R\$ (USD): 1.0 (0.31) \\
\hline
\end{tabular}

${ }^{a}$ USD values (In brackets) when the reported cost values were in other currencies calculated using historical exchange rates for the respective publication year's January

All studies were at high risk of bias. Many studies did not have control groups. Particular problems with interpreting data from uncontrolled studies are susceptibility to confounding (including seasonality) and regression to the mean [59]. There were two RCTs and although these were at high risk of bias too, they are more reliable than the other studies because of randomization. Both reported higher intake of fruits and vegetables in the intervention group, one providing a $3 \mathrm{~h}$ workshop on resource management and diet [34] and the other providing newsletters, fruits, vegetables, and pedometers along with walking goals [41]. These interventions could be implemented in shelter settings similar to those in the respective studies.

It was not possible to estimate cost effectiveness as none of the studies reported cost-effectiveness analysis. Limited data on intervention costs from four studies on food or supplement provision interventions indicate the costs of daily oral vitamin supplements to be lower than that of meals. However, this information without the benefits associated with each is of limited use when choosing between competing interventions, especially when these were not directly or concurrently compared.

There were no assessments of cognitive function in the included studies. Although this may be difficult to measure accurately, it is an important outcome which can affect people's ability to optimally use healthcare and housing services, which may require learning and remembering new things [60]. Long term outcomes in health are also missing from the literature. These outcomes can be useful for decision makers in establishing whether the interventions provided the intended benefit. Nutritional outcomes reported across studies were illdefined and variably measured. There are known issues in this area of research associated with use of convenient measures, transiency of the population, and the extreme variation in food intake dependent on donations or the opening days/ h of soup-kitchens or similar facilities [61, 62]. Future studies in this population should use more rigorous measures of nutritional change [62].

Nine studies reported use of incentives (cash or gifts) to increase data collection and uptake of intervention. This, along with high dropouts, suggests that effectiveness may not be entirely attributable to the intervention.

\section{Strengths and limitations}

Given that we expected limited evidence on the question, not using language restrictions and using an extensive grey literature search was a key strength of our review. This strategy was likely the reason we were able to identify a relatively large number of studies. We supplemented this exhaustive search with rigorous methods of inclusion and appraisal of the research identified. This makes our findings reliable. Another strength of this review lies in its inclusivity. This allowed for the unrestricted inclusion of and, consequently, the exploration of the range of interventions evaluated. The results of this review can therefore inform the implementation of these interventions to improve the health of homeless problem-drinkers in similar settings. No two studies of similar design assessed the same intervention and outcome and thus an expected limitation of this review was that results of the studies could not be combined in a meta-analysis. Thus the interpretation requires caution, especially considering the limitations in study quality. We therefore analysed interventions in broad categories and avoided subgrouping of results further.

\section{Applicability of evidence}

There are still lessons to be learnt from this limited evidence base and implications for policy and research, although caution is required when implementing this evidence. 
Most interventions were set in shelters and inclusion often restricted to shelter dwellers. No study assessed an intervention for rough sleepers alone. This group often gets excluded from such research studies due to their transient location, yet they may have more complex needs [61], so their inclusion in future research would be valuable. Although some shelters do, not all will accept rough sleepers who are heavy alcohol or drug users [45, 63]. Rough sleepers with drinking or drug problems also sometimes avoid engaging with shelters [64]. Healthcare access points, such as general practices offering primary health care services to street drinkers may be a more inclusive setting to reach this subgroup [61]. Even when these are free at point of delivery, it could mean uneven reach where the most vulnerable homeless drinkers may be unaware of or unable to reach these services.

Although, education and training can raise awareness in and provide information to homeless people to make healthier food choices, it is harder for homeless people to make these healthy choices when they have no kitchen, cupboard, or fridge, and move residence frequently $[39,44]$. In addition, vitamin B1 deficiency with heavy drinking over time leads to cognitive impairment [65]. Once in this state, any counselling or health promotion efforts to bring about behaviour change would be less likely to work [66]. Thiamine intake can often reverse this impairment [67]. Alcohol and/or drug support services often pursue harm reduction interventions (e.g. needle exchange) alongside interventions to reduce substance abuse [68]. These services could also consider providing nutritional interventions for preventing or treating malnutrition in the homeless, heavy drinking population.

Our findings suggest that consideration for local taste preferences is important in meal provision services. However, only one study [58] reported developing the content of the food rations according to local food tradition. Meal provision was an acceptable intervention although evidence suggested that it may not always fulfil energy needs. Meal services require a full kitchen and catering staff to serve meals every day. In addition, there is evidence that nutritional value of these meals may be constrained by resources and prioritising a satisfying meal over nutritional value by both providers and users [57]. No included study compared different types of food and/or supplement provision interventions and this should be assessed in future for comparative benefit and resources use.

Provision of kitchen facilities in two studies appeared to be effective in improving nutritional intake. It led to a reduction in vitamin deficiencies in one study in homeless families [45]. The other study [47] that made kitchens available to street-living homeless as well as the shelter participants reported that the participants enjoyed cooking, and the use of the kitchen facilities increased rapidly. This indicates that the lack of these facilities might be a key factor in malnutrition among homeless drinkers [18]. It also suggests that experiential learning may be more effective than giving nutritional advice in this client group [44].

It seems that an educational intervention with a cooking competition proposed by the shelter staff alone had low uptake [48], but an intervention developed with service user input, involving education, kitchen facility and communal dining was popular [47]. Involving the population in research can increase participation rates and user controlled research is encouraged in public health and social care research [69]. Considering the difficulty in accessing homeless drinkers, their involvement in a project aimed at their health can improve uptake and measuring of the impact and continuity of service later. This would also give choice to a marginalised population.

Nine studies included only homeless women with children or homeless families [34, 36, 38-40, 42-45]. These studies may therefore be less representative of the typical demographics of the homeless problemdrinking population in urban settings in Europe [70] and North America [71, 72] which is largely single male. Male homeless population was included in two studies exclusively $[54,56]$ and five others had more than $80 \%$ men $[35,46,47,55,58]$. Gender differences have been seen in the homeless regarding use of health services [73, 74]. Learning the composition and preferences of the target population before setting up an intervention and tailoring the intervention to the local demographics is therefore warranted. This will ensure optimal uptake and consequently the likelihood of intervention success.

The services for homeless problem drinking people are likely varied across the globe. In the USA, the United States Interagency Council on Homelessness (USICH) is responsible for reducing homelessness [75]. It is an independent agency of the federal government designed to coordinate a response in partnership with state and local governments, and community groups. In the UK services to the homeless are provided by local councils under the guidance provided by the Department for Communities and Local Governments [76] and by charities such as Crisis, Pathway, Salvation Army, and Shelter. This means that services and their structure vary across regions. In the UK, these services are also over stretched in the face of current political and economic situation and the housing crisis since 2008, which means fewer resources are available to address malnutrition for problem drinking subgroups of homeless people. 
With limited available funds, the variations in services across settings and locations can serve as an alternative to a traditional comparative study. This can identify the most beneficial interventions for a specific outcome and/or setting. Thus in future, in addition to randomized designs, natural experiments such as those designed around a change in local or regional policy, a practice within a certain hospital or a charity organisation, can provide evidence that is more applicable in terms of effectiveness. These findings should then be reported in an accessible location and format to reduce publication bias.

\section{Conclusions}

With the high risk, single study data on any of the studied interventions we cannot conclude which intervention may be most effective or cost effective for tackling malnutrition in homeless problem-drinkers. Nevertheless, several interventions appeared able to change nutrition related behaviour in a given setting and were acceptable. Decision makers need to carefully consider which of these interventions would translate well into their own setting and population for achieving a desired outcome. Including the target population in developing intervention content and delivery may optimise intervention success.

Better quality data and long terms outcomes such as malnutrition levels, health and disease status are also needed. Comparative cost and resource use should be part of any future intervention evaluation.

\footnotetext{
Abbreviations

ALT: Alanine transaminase; AST: Aspartate transaminase; B1: Thiamine; B12: Cobalamins; B2: Riboflavin; B3: Niacin; B5: Pantothenic acid; B6: Pyridoxine; B7: Biotin; B9: Folic acid; C: Ascorbic acid; EPOC: Cochrane Effective Practice and Organisation of Care; F: Female; G: Gram; Gp: Group; Hb: Haemoglobin; IQR: Interquartile range; Kcal: Kilocalories; k: Kilojoules; L: Litre; M: Male; MD: Mean difference; Mg: Milligram; Mmol: Millimoles; N: Number of participants; Nmol: Nanomoles; NR: Not reported; NV: No vitamin; P5P: Pyridoxal 5 phosphate; Pmol: Picomoles; RCT: Randomised controlled trial; SD: Standard deviation; TDP: Thiamine diphosphate; Tk: Transketolase; TPP: Thiamine pyrophosphate; UBA: Uncontrolled before and after study; V: Vitamin; Mmol: Micromoles
}

\section{Acknowledgements}

Not applicable

\section{Funding}

This work was supported by National Institute for Health Research (NIHR) Collaboration for Leadership in Applied Health Research and Care West (CLAHRC West) at University Hospitals Bristol NHS Foundation Trust. The views expressed are those of the authors and not necessarily those of the NHS, the NIHR or the Department of Health.

JK is partly funded by National Institute for Health Research (NIHR) Collaboration for Leadership in Applied Health Research and Care West (CLAHRC West) at University Hospitals Bristol NHS Foundation Trust and NIHR Health Protection Research Unit in Evaluation of Interventions.

\section{Availability of data and materials}

All data generated or analysed during this study are included in this published article [and its supplementary information files].

\section{Authors' contributions}

$\mathrm{KP}, \mathrm{CF}, \mathrm{JS}, \mathrm{EM}, \mathrm{HT}$ and $\mathrm{SI}$ designed the study. JK, LM, and TJ contributed to screening, data extraction, and risk of bias assessments. SI, KP, CF, TJ and JS contributed to narrative synthesis. AR developed and conducted the searches. SI drafted the manuscript and all authors critically revised the manuscript and approved the final version.

Ethics approval and consent to participate

Not applicable

Consent for publication

Not applicable

\section{Competing interests}

The authors declare that they have no competing interests.

\section{Publisher's Note}

Springer Nature remains neutral with regard to jurisdictional claims in published maps and institutional affiliations.

\section{Author details}

${ }^{1}$ The National Institute for Health Research Collaboration for Leadership in Applied Health Research and Care West (NIHR CLAHRC West) at University Hospitals Bristol NHS Foundation Trust, 9th Floor Whitefriars, Lewins Mead, Bristol BS1 2NT, UK. Bristol Medical School, Population Health Sciences, University of Bristol, Bristol, UK. ${ }^{3}$ City Hall, Bristol BS1 5TR, UK. ${ }^{4}$ Compass Health, The Compass Centre, 1 Jamaica Street, Bristol BS2 8JP, UK. ${ }^{5}$ The National Institute for Health Research Health Protection Research Unit in Evaluation of Interventions, London, UK. ${ }^{6}$ Bristol Medical School,

Musculoskeletal Research Unit, Translational Health Sciences, University of Bristol, Bristol, UK.

Received: 11 September 2017 Accepted: 8 January 2018 Published online: 16 January 2018

\section{References}

1. Fazel S, Khosla V, Doll H, Geddes J. The prevalence of mental disorders among the homeless in western countries: systematic review and metaregression analysis. PLoS Med. 2008;5:e225.

2. Magura S, Nwakeze PC, Rosenblum A, Joseph H. Substance misuse and related infectious diseases in a soup kitchen population. Subst Use Misuse. 2000;35:551-83.

3. Fitzpatrick S, Pawson H, Bramley G, Wilcox S, Watts B. The homelessness monitor: England 2017. In: Homeless monitor. London: Crisis; 2017.

4. Problem Drinking vs. Alcoholism: What's the Difference? [https:// talbottcampus.com/problem-drinking-vs-alcoholism-whats-the-difference/]

5. Alcoholism and Problem Drinking [https://patient.info/health/alcoholismand-problem-drinking].

6. Social Drinking vs. Problem Drinking [https://www.urmc.rochester.edu/ encyclopedia/content.aspx?contenttypeid=1\&contentid=870]

7. Problem Drinker Defined [http://alcoholrehab.com/alcoholism/problemdrinker-defined/].

8. What's "at-risk" or "heavy" drinking? [https://www.rethinkingdrinking.niaaa. nih.gov/How-much-is-too-much/ls-your-drinking-pattern-risky/Whats-At-RiskOr-Heavy-Drinking.aspx].

9. Coppenrath W. Problems in nutritional status among homeless populations: an introduction. Nutr Bytes. 2001;7. https://escholarship.org/uc/item/ $5 \mathrm{hm} 1 \mathrm{p} 27 \mathrm{p \# main}$.

10. Darmon N, Coupel J, Deheeger M, Briend A. Dietary inadequacies observed in homeless men visiting an emergency night shelter in Paris. Public Health Nutr. 2001:4:155-61.

11. Tse C, Tarasuk V. Nutritional assessment of charitable meal programmes serving homeless people in Toronto. Public Health Nutr. 2008;11:1296-305

12. Bode C, Bode JC. Alcohol's role in gastrointestinal tract disorders. Alcohol Health Res World. 1997;21:76-83.

13. Victor $M$. The effects of alcohol on the nervous system: clinical features, pathogenesis, and treatment. In: Lieber CS, editor. Medical and nutritional complications of alcoholism: mechanisms in management. New York: Plenum Publishing Corp; 1992. p. 413-57.

14. Leo MA, Rosman AS, Lieber CS. Differential depletion of carotenoids and tocopherol in liver disease. Hepatology. 1993;17:977-86. 
15. Szabo G. Alcohol's contribution to compromised immunity. Alcohol Health Res World. 1997;21:30-41.

16. Wijnia JW, Oudman E, van Gool WA, Wierdsma Al, Bresser EL, Bakker J, van de Wiel A, Mulder CL. Severe infections are common in thiamine deficiency and may be related to cognitive outcomes: a cohort study of 68 patients with Wernicke-Korsakoff syndrome. Psychosomatics. 2016;57:624-33.

17. Sprake EF, Russell JM, Barker ME. Food choice and nutrient intake amongst homeless people. FASEB J. 2013;27

18. Coufopoulos A, Mooney K: Food, nutrition and homelessness. Guidance for practitioners. pp. 1-24. London: The Queen's Nursing Institute; 2012:1-24.

19. Salaspuro M. Nutrient intake and nutritional status in alcoholics. Alcohol Alcohol. 1993;28:85-8.

20. Elia M: The cost of malnutrition in England and potential cost savings from nutritional interventions. pp. 96: British Association for Parenteral and Enteral Nutrition (www.bapen.org.uk) and National Institute for Health Research Southampton biomedical research Centre (www.uhs.nhs.uk/nihrbrc); 2015:96.

21. Richardson H. More than 250,000 are homeless in England - shelter. In: BBC News http://www.bbc.co.uk/news/education-38157410. BBC; 2016.

22. Fitzpatrick-Lewis D, Ganann R, Krishnaratne S, Ciliska D, Kouyoumdjian F, Hwang SW. Effectiveness of interventions to improve the health and housing status of homeless people: a rapid systematic review. BMC Public Health. 2011;11:638.

23. Speirs $V$, Johnson M, Jirojwong S. A systematic review of interventions for homeless women. J Clin Nurs. 2013;22:1080-93.

24. Hwang SW, Tolomiczenko G, Kouyoumdjian FG, Garner RE. Interventions to improve the health of the homeless - a systematic review. Am J Prev Med. 2005;29:311-9.

25. Day E, Bentham PW, Callaghan R, Kuruvilla T, George S. Thiamine for prevention and treatment of Wernicke-Korsakoff syndrome in people who abuse alcohol. Cochrane Database Syst Rev. 2013;(7):CD004033. https://doi. org/10.1002/14651858.CD004033.pub3.

26. Sayon-Orea C, Martinez-Gonzalez MA, Bes-Rastrollo M. Alcohol consumption and body weight: a systematic review. Nutr Rev. 2011;69:419-31.

27. National Institute for Health and Care Excellence. Nutrition support for adults: oral nutrition support, enteral tube feeding and parenteral nutrition clinical guideline [CG32]. In: National Collaborating Centre for Acute Care, editor. Endocrinal, nutritional and metabolic conditions: general and other. London: National Collaborating Centre for Acute Care; 2006.

28. Thorley H, Porter K, Fleming C, Jones T, Kesten J, Marques E, Richards A, Savović J. Interventions for preventing or treating malnutrition in problem drinkers who are homeless or vulnerably housed: protocol for a systematic review. Syst Rev. 2015;4:131.

29. Legal definition of homelessness [http://england.shelter.org.uk/get_advice/ homelessness/homelessness_-_an_introduction/legal_definition_of_ homelessness].

30. Higgins JPT, Altman DG, Gøtzsche PC, Jüni P, Moher D, Oxman AD, Savović J, Schulz KF, Weeks L, Sterne JAC: The Cochrane Collaboration's tool for assessing risk of bias in randomised trials. 2011.

31. Effective Practice and Organisation of Care Review Group. Suggested risk of bias criteria for EPOC reviews. In: EPOC resources for review authors. Oslo: Norwegian Knowledge Centre for the Health Services; 2015.

32. Amui J. Pathway enquiry. In: ljaz S, editor. Email response from 'Pathway, healthcare for homeless People' on enquiry about any unpublished studies from the organisation; 2017.

33. Goldman L. Research on nutrition of homeless people. In: Ijaz S, editor. Email from the study author (les Goldman) after learning about our review project; 2017.

34. Derrickson JP, Buchanan C, Asing GK, Okuma A. Lessons learned from the "spend less. Eat well. Feel better." program efficacy trial. J Nutr Educ Behav. 2003:35:30-6.

35. Grazioli VS, Hicks J, Kaese G, Lenert J, Collins SE. Safer-drinking strategies used by chronically homeless individuals with alcohol dependence. J Subst Abus Treat. 2015;54:63-8.

36. Hamm LA, Holden EW. Providing WIC services to homeless families. J Nutr Educ. 1999:31:224-9.

37. Helfrich CA, Aviles AM, Badiani C, Walens D, Sabol P. Life skill interventions with homeless youth, domestic violence victims and adults with mental illness. Occup Ther Health Care. 2006;20:189-207.

38. Heslin KC, Andersen RM, Gelberg L. Case management and access to services for homeless women. J Health Care Poor Underserved. 2003;14:34-51.
39. Johnson LJ, Myung EH, McCool AC, Champaner El. Nutrition education for homeless women - challenges and opportunities: a pilot study. J Foodserv Bus Res. 2009;12:155-69.

40. Kadoura WE. The brighter future for homeless families and their preschoolers' program in salt lake city, Utah. Diss Abstr Int. 2014;75:1-114.

41. Kendzor DE, Allicock M, Businelle MS, Sandon LF, Gabriel KP, Frank SG. Evaluation of a shelter-based diet and physical activity intervention for homeless adults. J Phys Act Health. 2016;14(2):88-97.

42. Richards R, Merrill RM, Baksh L, McGarry J. Maternal health behaviors and infant health outcomes among homeless mothers: U.S. special supplemental nutrition program for women, infants, and children (WIC) 2000-2007. Prev Med. 2011;52:87-94.

43. Rusness BA. Striving for empowerment through nutrition education. J Am Diet Assoc. 1993;93:78-9.

44. Rustad C, Smith C. Nutrition knowledge and associated behavior changes in a holistic, short-term nutrition education intervention with low-income women. J Nutr Educ Behav. 2013;45:490-8.

45. Wiecha JL, Dwyer JT, Jacques PF, Rand WM. Nutritional and economic advantages for homeless families in shelters providing kitchen facilities and food. J Am Diet Assoc. 1993;93:777-83.

46. Drijver E, Van Strik R. Influence of intramuscular vitamin-B supplementation on TK activity and TDP-effect in erythrocytes in alcoholics. [Dutch]. TGO Tijdschrift Ther Geneesmiddel en Onderzoek. 1993;18:132-7.

47. Tarasuk V, Woolcott L. Food acquisition practices of homeless adults: insights from a health promotion project. J Can Diet Assoc. 1994;55:15-9.

48. Hinton T, Evans N: Healthy hostels: a guide to promoting health and wellbeing among homeless people. pp. 46pp. London: Crisis; 2001:46pp.

49. Stewart $M$, Reutter $L$, Letourneau N, Makwarimba E. A support intervention to promote health and coping among homeless youths. Can J Nurs Res. 2009;41:55-77.

50. Bonevski B, Baker A, Twyman L, Paul C, Bryant J. Addressing smoking and other health risk behaviours using a novel telephone-delivered intervention for homeless people: a proof-of-concept study. Drug Alcohol Rev. 2012;31:709-13.

51. Murakami YCA, Almeida Dos Santos J, De Camargo M, Sandoval T, Freiberg C. Food intake assessment of the 'bom prato' project users. Ann Nutr Metab. 2013;63:426-7.

52. Allen L, O'Connor J, Amezdroz E, Bucello P, Mitchell H, Thomas A, Kleve S, Bernardi A, Wallis L, Palermo C. Impact of the social cafe meals program: a qualitative investigation. Aust J Prim Health. 2014;20:79-84.

53. Barbour LR, Ho MYL, Davidson ZE, Palermo CE. Challenges and opportunities for measuring the impact of a nutrition programme amongst young people at risk of food insecurity: a pilot study. Nutr Bull. 2016;41:122-9.

54. Darnton-Hill I, Sriskandarajah N, Craig GK, Truswell AS. Vitamin status of homeless men. Proc Nutr Soc Aust. 1986;11:99.

55. Patino Villena B, Navarro Garcia A, Periago Caston MJ, Rodriguez Tadeo A, Duarte Lopez A, Ros Berruezo G, Gonzalez Martinez-Lacuesta E. Sensory and nutritional evaluation of a municipal service of community kitchen for poor and homeless persons. Ann Nutr Metab. 2013;63:1075.

56. Darmon N. A fortified street food to prevent nutritional deficiencies in homeless men in France. J Am Coll Nutr. 2009;28:196-202.

57. Pelham-Burn SE, Frost CJ, Russell JM, Barker ME. Improving the nutritional quality of charitable meals for homeless and vulnerable adults. A case study of food provision by a food aid organisation in the UK. Appetite. 2014;82:131-7.

58. Garden B, Samarina A, Stavchanskaya I, Alsterlund R, Ovregaard A, Taganova O, Shpakovskaya L, Zjemkov V, Ridell M, Larsson LO. Food incentives improve adherence to tuberculosis drug treatment among homeless patients in Russia. Scand J Caring Sci. 2013;27:117-22.

59. Armstrong R, Waters E, Doyle J. Chapter 21: reviews in health promotion and public health. In: JPT H, editor. Cochrane handbook for systematic reviews of interventions version 510 (updated march 2011). GS: The Cochrane Collaboration; 2011.

60. Backer TE, Howard EA. Cognitive impairments and the prevention of homelessness: research and practice review. J Prim Prev. 2007;28:375-88.

61. Evans NS, Dowler EA. Food, health and eating among single homeless and marginalized people in London. J Hum Nutr Diet. 1999;12:179-99.

62. Seale JV, Fallaize R, Lovegrove JA. Nutrition and the homeless: the underestimated challenge. Nutr Res Rev. 2016;(2):143-151.

63. Krüsi A, Fast D, Small W, Wood E, Kerr T. Social and structural barriers to housing among street-involved youth who use illicit drugs. Health Soc Care Community. 2010;18:282-8. 
64. Diaz R: Street homelessness factsheet. (England S ed. pp. 15. London: Shelter; 2006:15.

65. Abdou E, Hazell AS. Thiamine deficiency: an update of Pathophysiologic mechanisms and future therapeutic considerations. Neurochem Res. 2015;40:353-61.

66. Bernardin F, Maheut-Bosser A, PAILLE F. Cognitive impairments in alcoholdependent subjects. Front Psychiatry. 2014;5:78.

67. Day E, Bentham PW, Callaghan R, Kuruvilla T, George S. Thiamine for prevention and treatment of Wernicke-Korsakoff syndrome in people who abuse alcohol. Cochrane Database Syst Rev. 2013;7:CD004033.

68. National Treatment Agency for Substance Misuse: Harm reduction strategy - guidance to support adult drug treatment planning and self audit tool revised guidance for 2009/10 (England PH ed. pp. 1-23. London: National Treatment Agency for Substance Misuse, 2009:1-23.

69. Turner M, Beresford P. User controlled research its meanings and potentialfinal report. INVOLVE: Hants; 2005.

70. Busch-Geertsema V, Benjaminsen L, Hrast M, Pleace N. Extent and profile of homelessness in European member states: a statistical update. In: European observatory on homelessness(EOH) comparative studies on homelessness. FEANTSA's European Observatory on Homelessness: Brussles; 2014.

71. Gaetz S, Donaldson J, Richter T, Gulliver T. The state of homelessness in Canada. In: Homeless hub paper; 2013.

72. Henry M, Watt R, Rosenthal L, Shivji A. The 2016 annual homeless assessment report (AHAR) to congress. The U.S. Department of Housing and Urban Development, Office of Community Planning and Development: MA, USA; 2016.

73. DiBlasio FA, Belcher JR. Gender differences among homeless persons: special services for women. Am J Orthop. 1995;65:131-7.

74. Health Needs Audit: Health service use among the homeless population [http://www.homeless.org.uk/facts/homelessness-in-numbers/health-needsaudit-explore-data].

75. United States Interagency Council on Homelessness Fact Sheet [https:// www.usich.gov/tools-for-action/usich-fact-sheet].

76. Department for Communities and Local Government. In: health Do, editor. Homelessness code of guidance for local authorities. London: Department for Health; 2006.

\section{Submit your next manuscript to BioMed Central and we will help you at every step:}

- We accept pre-submission inquiries

- Our selector tool helps you to find the most relevant journal

- We provide round the clock customer support

- Convenient online submission

- Thorough peer review

- Inclusion in PubMed and all major indexing services

- Maximum visibility for your research

Submit your manuscript at www.biomedcentral.com/submit 